\title{
Assessing the efficacy and effectiveness of a Positive Psychology- based self-help book
}

\author{
Evaluación de la eficacia y la efectividad de un libro de autoyuda basado en Psicología \\ Positiva
}

\author{
Acacia C. Parks \\ $\&$ \\ Rebecca K. Szanto \\ Hiram College, USA
}

(Rec: 16 Enero 2013 / Acep: 29 Enero 2013 )

\begin{abstract}
The current article discusses the potential utility of self-help books as a means of disseminating positive psychological interventions, and presents data comparing a positive psychology-based self-help book with a cognitive-behavioral self-help book and a self-monitoring control condition. We studied college freshmen $(\mathrm{N}=58)$, and argue that this population is a particularly appropriate target for well-being intervention. Outcome measures included both indices of efficacy (depressive symptoms and life satisfaction) and effectiveness (e.g. the extent to which participants found their assigned activities to be meaningful). The two book groups outperformed the control and were equivalently efficacious at reducing depressive symptoms; on life satisfaction, positive self-help outperformed cognitive-behavioral, but only at 6-month follow-up. Positive self-help was also superior to cognitive-behavioral self-help on indices of effectiveness. Possibilities for future directions are discussed, with an emphasis on the realities of practical dissemination to both college students, and to the general public.
\end{abstract}

Key words. self-help books, positive psychological interventions, efficacy, effectiveness

\section{Resumen}

El presente artículo analiza la utilidad potencial de los libros de auto-ayuda como medio de difusión de las intervenciones psicológicas positivas, y presenta datos comparando libro de autoayuda basado en psicología positiva, un libro de autoayuda cognitivo-conductual, y una condición de control de auto-monitorización. Participaron estudiantes universitarios de primer año $(\mathrm{N}=58)$, y defendemos que esta población es un objetivo particularmente apropiado para intervenciones centradas en el bienestar. Las medidas de resultado incluyeron tanto índices de eficacia (síntomas depresivos y satisfacción con la vida) como de efectividad (por ejemplo, el grado en el que los participantes juzgaron que sus actividades asignadas tenían sentido). Los dos grupos de libros superaron al grupo control y fueron igualmente eficaces en la reducción de los síntomas. Respecto a la satisfacción vital, el grupo de autoayuda positiva superó al cognitivo-conductual, pero sólo a los 6 meses de seguimiento. La intervención positiva de auto-ayuda también fue superior a la cognitivo-conductual en los índices de efectividad. Se discuten las posibilidades de futuras direcciones, enfatizando las realidades de la difusión práctica tanto en estudiantes universitarios como al público en general.

Palabras Clave: libro de autoyuda, intervenciones psicológicas positivas, eficacia, efectividad 


\section{Introduction}

The last decade has seen tremendous growth in the study of psychological interventions for increasing happiness. These interventions target myriad positive psychological constructs, including strengths, social connections, meaning, forgiveness, gratitude, empathy, and savoring (Parks \& Biswas-Diener, in press). A rapidly expanding literature suggests that a number of different Positive Psychological Interventions (PPIs) reliably decrease depressive symptoms among individuals who use them (see Parks \& BiswasDiener, in press for a comprehensive and up-to-date review). Recent research has begun to fine-tune this literature by investigating important topics such as person-activity fit (Schueller, 2010), as well as the role of hedonic adaptation in the long-term sustainability of happiness interventions (Sheldon \& Lyubomirsky, 2012). Another important next step, however, is to determine ways to disseminate these interventions to the general public in ways that are financially and logistically feasible (Parks, Schueller \& Tasimi, 2012).

In this paper, we will argue that self-help books are one important vehicle by which PPIs can be successfully delivered to consumers. We will do this using a particular population whom we happen to have studied - college freshmen - as a backdrop. We will therefore begin by outlining our reasoning for choosing to do this work in college freshmen. We will then provide some background on the history of self-help book based interventions (i.e. bibliotherapy) in the clinical psychology literature, where they have been most prominently studied. Lastly, we will describe a preliminary study that we conducted investigating the efficacy and effectiveness of a positive psychology-based self-help book for young adults in their first year of college.

\section{Why Target College Freshmen?}

The transition to college is a stressful time for many young adults, and difficulty coping with stress leads to poorer social and academic adjustment among college students (Friedlander, Reid, Shupak \& Cribbie, 2007). Stress compounds itself, causing psychological symptoms, which in turn cause more stressful situations (Compas, Wagner, Slavin \& Vannatta, 1986); for example, a student might do poorly on a test due to test anxiety, and that poor grade then becomes yet another source of stress. Furthermore, 75\% of new freshmen report feeling lonely during their first 2 weeks of college (Cutrona, 1982), and that loneliness is a risk factor for depressive symptoms (Wolf, Scurria, \& Webster, 1998; Joiner, 1997). Depressive symptoms, even at subclinical levels, cause significant impairment in everyday life (Flett, Vredenburg, \& Krames, 1997; Judd, Akiskal \& Paulus, 1997). Of particular concern for college students is the symptom of decreased interest; lack of engagement with one's college environment - both academically and socially - predicts student attrition (Milem \& Berger, 1997). Attrition is a serious problem in higher education, with an average of only $53 \%$ of students at 4 -year institutions graduating (Carey, 2004). A significant amount of that attrition happens during the first year (ACT, 2004), so it is important to intervene early, and to address not only academic factors, but emotional difficulties as well.

\section{Group-Based Resilience Interventions in College Freshmen}

The first positive psychology interventions for college students were designed with the goal of preventing depression. Seligman, Schulman, DeRubeis \& Hollon (1999) offered a manualized, 8-week cognitive-behavioral program to college freshmen who were deemed at risk by virtue of their pessimistic explanatory style (Abramson, Seligman \& Teasdale, 1978). The goal of the study was to improve explanatory style so as to decrease depression risk. While that study had only modest effects, a replication by Seligman, Schulman, \& Tryon (2007) took a slightly different approach - targeting students who were not only at risk for depression, but who were already suffering from subclinical depressive symptoms. Because subclinical symptoms are a more robust predictor of clinical levels of depression later on, and because, as discussed above, subclinical symptoms cause real impairment in college students' functioning, there was more potential for the program to lead to clinically significant benefits to the students. Although the intervention for this second study was essentially the same ${ }^{1}$, the tone of the paper in which the second study's data were presented represented a shift from a "prevention" approach to an emphasis on "wellness promotion;" the main outcomes were depressive symptoms - which significantly decreased - and well-being - which significantly increased.

Observing the significant impact that a cognitivebehavioral intervention had on well-being, an offshoot of that research group designed a new manualized group intervention that targeted well-being directly and offered

\footnotetext{
${ }^{1}$ The intervention had a web-based component, but usage of the web system was very low; the intervention was, for all intents and purposes, identical to that used in the previous study.
} 
it to incoming freshmen (see Parks-Sheiner, 2009 for the manual $^{2}$ ). They found significant improvements in depressive symptoms and life satisfaction, and the effect sizes for those improvements were almost three times that of the cognitive-behavioral program (Seligman, Rashid \& Parks, 2006). Those findings were replicated by Parks-Sheiner (2009) in a sample of students that included college students of all years; interestingly, effect sizes were smaller in that sample, suggesting perhaps that well-being interventions might be especially impactful among freshmen, who are acutely experiencing a new and stressful life transition.

The findings from the group PPI in college freshmen are particularly compelling in light of recent research on the benefits of happiness - which include better relationships, job performance, and goal attainment in life. These findings suggest that it is worthwhile to actively promote positive emotion rather than simply remediating distress (Lyubomirsky, King \& Diener, 2005). Studies in college settings find that students who experience positive emotion study more, and students who study more then experience further positive emotion (Ouweneel, Le Blanc \& Schaufeli, 2011). Furthermore, there appears to be significant room for improvement; an estimated $21 \%$ of college students report high well-being, that $21 \%$ works harder and does better in school compared to the $19 \%$ who report low well-being or the $60 \%$ who fall somewhere in between (Howell, 2009). Therefore, it seems that positive psychology-based interventions have their own unique potential - in addition to, or instead of cognitive-behavioral interventions - as a way to prevent depression and improve well-being in freshmen.

\section{A Case for Self-Help Interventions}

As described above, while a handful of previous studies have attempted to prevent depressive symptoms in college freshmen, these studies have typically involved large-scale, time- and effort-intensive interventions; participants in these studies attended in-person workshops, led by licensed clinicians, over the course of 6-8 weeks and were given homework assignments, which were collected by workshop leaders as an incentive to comply. While these programs lead to significant reduction of depression risk (e.g. reduced depressive symptoms), realistic implementation of such a costly format of intervention in a college setting remains a real logistical obstacle, especially at small colleges where

\footnotetext{
${ }^{2}$ The manual can also be downloaded at http://acacia.parks.socialpsychology.org/publications
}

programming budgets can be more modest. Therefore, the idea of a self-help interventions - and book-based interventions, in particular, which are quite affordable at $\sim \$ 12$ per person - is quite appealing. There is much past precedent for the idea of using book-based interventions, a practice called bibliotherapy, in the cognitive-behavioral literature (Ackerson et al., 1998; Naylor et al., 2010). Cognitive-behavioral bibliotherapy has been found to be not only effective, but in some cases comparable to traditional in-person therapy (Cuijpers, 1997), and so it has great promise as an approach for widespread dissemination of psychological interventions.

Paralleling research on cognitive-behavioral interventions for college freshmen described above, Parks (2003) conducted a small pilot study in which they sought to apply Seligman, Schulman, DeRubeis \& Hollon (1999) in a way that was financially feasible for a small college - via a selfhelp book. They conducted a study in which a sample of college freshmen $(\mathrm{N}=65)$ were randomly assigned to either receive a cognitive-behavioral self-help book (Control Your Depression; Lewinsohn, Muñoz, Youngren \& Zeiss, 1992) or be in a wait-list control condition. While the groups were not significantly different at post-test, participants in the control group experienced increased symptoms between post-test and the follow-ups (3-week, 2-month and 6-month) while the group who had used the self-help book stayed the same (Parks, 2004); this suggests that the intervention had a "buffering" effect, preventing those who experienced it from experiencing the increases in depressive symptoms that were experienced by the control group. Self-help participants also experienced an increase in subjective happiness, which remained through 6-month follow-up (Parks, 2003).

To our knowledge, no other research has examined the utility of book-based interventions for college freshmen. It was our goal to extend this initial pilot study to include a direct comparison between Control Your Depression, a representative cognitive-behavioral book, and a positive psychology-based book, The How of Happiness. Based on previous research, outlined above, we expected that the positive self-help book would be equivalent or superior to the cognitive-behavioral self-help book on indices of efficacy (depressive symptoms, life satisfaction). Furthermore, based on initial findings by Seligman, Rashid and Parks (2006) suggesting that adherence rates were better on a positive intervention as compared to a treatment-as-usual, we expected positive self-help to be superior to the cognitive-behavioral self-help book on indices of effectiveness (i.e. participant preference). 


\section{Method}

\section{Participants}

Participants were 58 freshmen students at Hiram College, a rural liberal arts school in the Midwest. The sample was $64 \%$ female, $22 \%$ male, with $13.6 \%$ not reporting their gender. $67.8 \%$ of the sample identified as Caucasian/white, while $5.1 \%$ were African American and Multiracial, respectively, and $1.7 \%$ were Indigenous/Aboriginal, Asian/Pacific Islander, Hispanic, or Latino, respectively. An additional 17\% did not answer the question about ethnicity or indicated that they would rather not say.

On average, the sample reported moderate depressive symptoms $(M=19.76$, sd $=5.77)$. To assess the extent to which these baseline levels are typical, we provide means from representative samples reported by Radloff (1991) for comparison. While our sample reported symptoms substantially higher than the adult average $(M=8.97, \mathrm{sd}=8.50)$, it is only somewhat higher than the expected average for this age group, which should lie somewhere between that of high school students $(\mathrm{M}=17.88, \mathrm{sd}=10.31)$ and of college students $(\mathrm{M}=15.46, \mathrm{sd}=9.67)$ (Radloff, 1991). It is quite a bit lower than the average seen in an acutely depressed sample $(M=38.07, \mathrm{sd}=9.00)$, but interestingly, somewhat comparable to the average CES-D score reported by a sample of happiness seekers on the internet $(\mathrm{M}=17.44, \mathrm{sd}=12.72)$.

The average life satisfaction of our sample was 25.93 (sd $=5.42$ ), which is nearly identical to one of five American college student samples reported by Pavot and Diener (1993), and 1-2 points higher than the remaining four samples.

\section{Procedure}

Participants completed a consent form in compliance with the Hiram College Institutional Review Board, then completed a set of baseline questionnaires. They were then randomly assigned to one of three groups: positive selfhelp $(\mathrm{N}=20)$, cognitive-behavioral self-help $(\mathrm{N}=20)$, and a control group that recorded their own naturally-occurring happiness-promoting behaviors $(\mathrm{N}=18)$. In both self-help groups, participants received a copy of the assigned book and a syllabus detailing a plan for reading the book and completing the exercises it contains over the course of 8 weeks.

During the course of that 8 -week period, all participants (including controls) completed weekly web-based assessments on their mood and, if relevant, compliance with the assigned activities. At the end of the 8-week period, participants completed a longer post-survey containing the same questionnaires as were given at baseline. Participants were given $\$ 25$ each upon completion of the post-survey. 6 months later, participants were contacted for additional follow-up questionnaires; they were not compensated for this follow-up.

\section{Instruments}

Demographic survey. At baseline assessment, participants were asked to report their gender, as well as their race/ethnicity.

Depressive symptoms. Depressive symptoms were measured using the Center for Epidemiological Studies Depression Scale (CES-D; Radloff, 1977). The scale consists of 20 items and has a high internal consistency $(\alpha=.85)$. The scale ranges from 0 to 60 , with 16 as a standard cutoff for clinical severity levels. The general population has an average score between 8 and 9. Participants are asked to respond to the question: "How often have you felt this way during the past week?" Participants rate responses on a scale of 0-3 (0- rare, 3- most of or all of the time). Some sample questions include: "I was bothered by things that usually don't bother me" or "I had trouble keeping my mind on what I was doing."

Life satisfaction. Satisfaction with life was measured using the Satisfaction with Life Scale (SWLS; Diener, Emmons, Larsen, \& Griffin, 1985). The SWLS has a high internal consistency $(\alpha=.87)$. The scale is a 7-point likert scale with 1 representing strongly disagree and 7 strongly agree. Participants can score between 5 and 35, with 5 representing low satisfaction and 35 being high satisfaction. The average score in the general population is between 23 to 28. These ranges encompass "slightly satisfied" to "satisfied". Participants decide how much they agree with the statements presented in on the scale. There are five questions on the scale. An example of a question would be "In most ways my life is close to my ideal" or "I am satisfied with my life." The higher an individual's score on the SWLS, the higher their satisfaction with life (Diener et al., 1985).

Preference. We created a scale to measure participants' preferences for the activities in their assigned condition. After each week of the intervention period, participants were asked to answer five questions about their reaction to the week's activity: 1) How often did you use this activity?, 2) How much did you enjoy this activity?, 3) How effective did you think this activity was?, 4) How meaningful was this activity to you? and 5) How confident are you that 
this activity could be used in the future to help regulate or change your mood?

Answers to each of the five questions - which addressed frequency of use, enjoyment, perceived effectiveness, perceived meaningfulness, and confidence in future effectiveness, respectively- were averaged across the eight weeks into a single index, yielding five indices of preference.

\section{Experimental Conditions}

Positive Self-Help. The first group read The How of Happiness by Sonja Lyubomirsky (2007). The How of Happiness bases its lessons on the belief that $40 \%$ of an individual's happiness can be altered through their own actions and decisions. Through the use of 12 happinessenhancing strategies, the author directs readers in how to improve their lives through increasing happiness.

In the current study, we asked participants to focus on four specific chapters: "Practicing Gratitude and Positive Thinking", "Investing in Social Connections", "Managing Stress, Hardship, and Trauma", and "Living in the Present." Each chapter highlights different activities that readers engage in when learning about the chapter's lessons. For example, in "Living in the Present" readers are prompted to "Savor Life's Joys." The author challenges readers to "celebrate good news" and "replay happy days."

Cognitive-Behavioral Self-Help. The second group read Control Your Depression (Lewinsohn et al.,1992). Control Your Depression is a book designed to help those currently suffering from depression, at risk for depression, or having past episodes of depression shorten the length of depression episodes and fight against new episodes. It was used successfully in a previous pilot study, discussed above, in non-depressed but at-risk college freshmen (Parks, 2003).

The book is divided into three sections. Part I focuses on "The Concepts" and guides readers through what depression exactly is and how to think about it. Part II outlines "The Strategies" that readers should use when managing their depression. Part III, "Looking Toward the Future" offers readers advice and guidance in how to practice and maintain what they have learned while reading the book and how to apply it to everyday life.

Control Group. The control group in this experiment received no intervention. Rather, they were asked to go about their normal daily routine, regulating their own happiness in whatever ways they do naturally, and recording the strategies they used.

\section{Results}

\section{Baseline Differences}

No differences that were significant or approaching significance were found between groups on primary outcome measures (depressive symptoms and life satisfaction).

\section{Dropout Rate}

While all participants who began the study completed post measures, there was dropoff between post and the 6-month follow-up such that the final sample sizes of the positive self-help ( $\mathrm{N}=13)$, cognitive-behavioral self-help $(\mathrm{N}=14)$ and control group $(\mathrm{N}=14)$ represent $71 \%$ of the original sample. There were no significant differences in dropout rates across the groups, nor did the participants who dropped out of the study differ significantly from participants who remained on baseline depressive symptoms or life satisfaction.

\section{Efficacy}

Differences in efficacy of the two intervention groups was assessed using a one-way Analysis of Variance (ANOVA) with either depressive symptoms or life satisfaction as the dependent variable and group membership (positive, cognitive-behavioral, or control) as the independent variable, controlling for baseline score. This type of endpoint analysis was conducted at each points - post and 6-month. Planned contrasts were used to determine the extent to which the two self-help groups differed from the control group, and from each other.

Depressive symptom change between pre and post assessments for each group is displayed in Figure 1. The overall ANOVA at this time point was significant, $\mathrm{F}[2,54]=$ $4.81, \mathrm{p}=.01$. Both the cognitive-behavioral self-help group

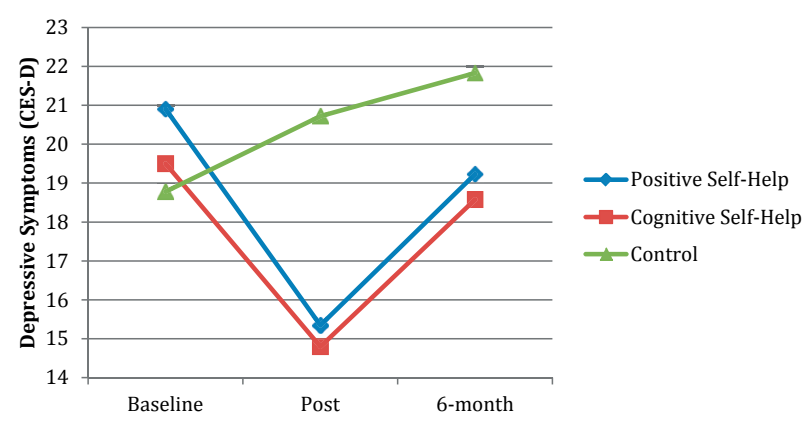

Figure 1. CES-D averages across groups at Pre, Post and 6-month assessments. 
$($ diff $=-5.86, p=.01)$ and the positive self-help group (diff $=-6.09, p=.01)$ were significantly superior to the control group, but the two self-help book groups were not significantly different from each other, nor did the difference approach significance $(p=.92)$. By 6-month follow-up, the effects of the self-help books had faded somewhat, and the difference between groups, though visibly apparent, was no longer statistically significant, although the difference between the positive self-help group and the control group did approach significance $(\operatorname{diff}=-7.10, \mathrm{p}=.09)$.

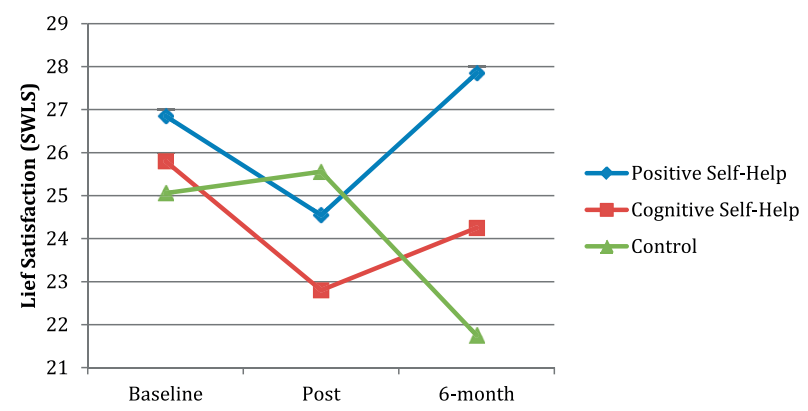

Figure 2. SWLS averages across groups at Pre, Post and 6-month assessments.

The pattern of means on the measure of life satisfaction followed a different trajectory. While no group experienced statistically significant change from pre to post, participants in the cognitive-behavioral self-help group seemed to experience a decrease in life satisfaction, as did the positive self-help group, though to a lesser extent, during the initial 8 -week intervention period. The control group, by contrast, remained level. By 6-month follow-up, however, this trend had reversed, with the positive self-help group reporting greater life satisfaction than the control group $(\operatorname{diff}=8.55, p$ $=.02$ ). Despite the significant contrast, the overall ANOVA only approached significance, $F[2,33]=3.13, p=.06$. This is most likely because the difference between positive self-help and cognitive-behavioral self-help was not significant, nor was the difference between cognitive-behavioral self-help and the control group. Overall, this pattern of data suggests - though only preliminarily - that the positive self-help book led to delayed long-term improvement in life satisfaction, while the other conditions (cognitive-behavioral self-help and control) did not.

\section{Effectiveness}

Independent sample t-tests were used to compare preference ratings between the positive and cognitive-behavioral self-help conditions. ${ }^{3}$ On the measure of perceived meaning, the positive self-help group rated their assigned activities significantly higher than did the cognitive-behavioral selfhelp group, $\mathrm{t}[29]=2.46, \mathrm{p}=.02$. Differences approaching significance were also observed on the measure of enjoyment $(\mathrm{t}[30]=1.95, \mathrm{p}=.06)$ and frequency of use $(\mathrm{t}[30]=1.79$, $\mathrm{p}=.08)$. Neither the differences in perceived effectiveness nor the differences in future confidence were significant, though only the confidence measure did not trend in the expected direction (see Figure 3).

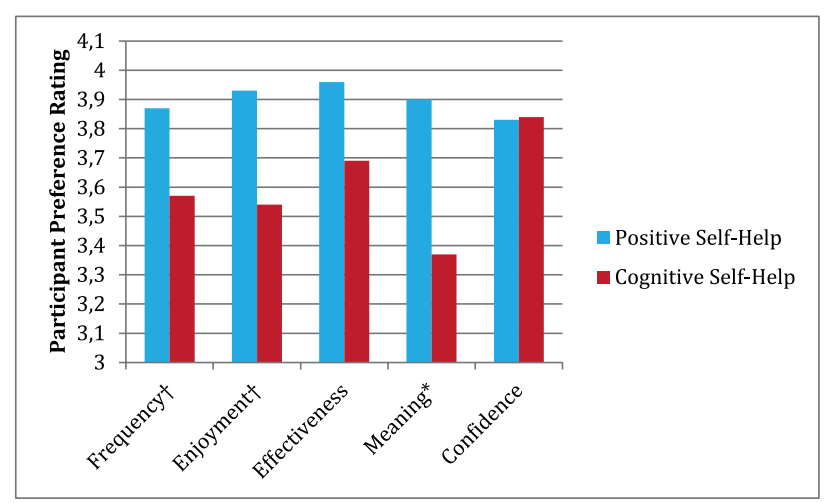

Figure 3. Participant preference ratings for positive versus cognitive self-help strategies, rated on a scale of 1-5.

Note. $*$ denotes statistically significant at $p<.05 .,+$ denotes approaching significance at $p<.1$

\section{Discussion}

The results of this preliminary study suggest that a positive psychology-based self-help book can lead to significant improvements in depressive symptoms and marginally significant improvements in life satisfaction when offered to college freshmen. These improvements were at least comparable to, if not in some ways better than, the improvements experienced by participants using an established cognitive-behavioral self-help book; furthermore, participants reported greater preference for the positive psychology-based self-help book, suggesting that it may have more potential as a tool that will realistically be integrated into the busy everyday lives of new college students.

\footnotetext{
${ }^{3}$ Not surprisingly, on four of the five indices of effectiveness - frequency of use, enjoyment, perceived effectiveness, and confidence in future effectiveness - participants preferred their own naturally-occurring happiness strategies over either of the books. This suggests, as Parks et al. (2012) and others have found, that participants do not necessarily know best when it comes to choosing self-help activities.
} 
Both group-based and self-administered PPIs have the potential to be disseminated to college freshman via freshman orientation programming. Parks (2003) recruited freshmen by setting up a table near the main orientation events; interested freshmen all had an equal opportunity to sign up. Seligman et al. (1999) and Seligman, Schulman and Tryon (2007) sent a mailing to all incoming freshmen, shortly after they received their college acceptance letters, inviting participation. In the present study, we recruited freshman by visiting first-year seminars. These strategies could be adopted by college counseling centers, or by colleges themselves. The University of Pennsylvania's Pre-Freshman program used this model in 2007, 2008 and 2009, offering incoming disadvantaged freshmen a chance to acclimate to college-level classes. One of the available classes was a positive psychology course, which both challenged students to do college-level work and also taught students the well-being skills included in Seligman, Rashid and Parks (2006)'s group PPI. Penn's first-year program is piloting a different model in the 2012-2013 academic year, offering a positive psychology book to a select number of first-year seminars as a common reading and then fostering the discussion of and engagement with the book's content across sections of the writing course.

Book-based programs offer a significant advantage over group-based programs in that they are cost-effective and can be completed by students in a flexible time frame. At the same time, group interventions offer a sense of community and accountability, as well as a chance for students to receive feedback and instruction from a group leader. Which of these two approaches is appropriate for a given program depends, then, on the needs of the institution, and the resources available; a group requires human labor, but a book-based approach requires an investment of $\sim \$ 12$ per student.

While, as argued above, there is certainly a need for well-being intervention in college students, the average happiness-based self-help seeker is not college-aged, but rather in their mid-late 30s (Parks et al., 2012), suggesting a need for work generalizing these findings to an adult population. Furthermore, while self-help books currently provide a widely-accessible and inexpensive option for individuals with limited financial means, as technology become more common and affordable, there is also great potential for the use of web-based (e.g. Schueller \& Parks, 2012) and smartphone-based (e.g. Parks et al., 2012) selfhelp programs using positive psychology content.

The current study contributes to the small but growing literature on research-grounded self-help that target happiness, but a number of questions remain to be addressed. First, while this paper did not explicitly address the mechanism by which the positive psychology-based self-help book worked, our results echoed a puzzling set of findings observed by Seligman, Rashid and Parks (2006): positive psychological interventions appear to have stronger effects on depressive symptoms, which are not targeted directly by the intervention (at least not intentionally), than on well-being variables like life satisfaction, which are explicitly targeted. This seems to suggest that positive interventions work by some mechanism that we do not fully understand. Future research could broaden the number of outcome variables examined to include not only depression and well-being measures, but other potential mechanisms such as social connections, health-related variables (e.g. sleep quality, energy levels), and goal attainment. A more holistic approach to assessing the effects of positive interventions may help to illuminate the mechanisms by which they are helpful.

Second, while in general, both self-help interventions seemed to outperform the control group, it is interesting to note that during the 8 -week intervention period, both self-help books seemed - though the trend was nonsignificant - to become less satisfied with life. This finding is particularly interesting given recent work by Mauss, Tamir, Anderson and Savino (2011), which suggests that in some contexts, deliberately trying to make oneself happier can undermine one's ability to do so successfully. Participants in this study were aware that the goal of the study was to improve their own well-being, so it is possible that this type of pressure had a mild deleterious effect in the short-term (though not in the long-term, at least for the happiness-based self-help book). It is also interesting in that this effect has not, to our knowledge, been observed in other similar studies (for example, Lyubomirsky et al., 2011, in which participants who were explicitly told that the study was intended to help them become happier improved more than did those who were not aware of the study's aims). Further research is needed to understand the circumstances in which a desire to become happier is an asset versus a hindrance.

On a related note, it is essential to examine not only the general efficacy of interventions, but the extent to which specific interventions are helpful for specific individuals. Recent work by Sergeant and Mongrain (2011) highlights the possibility that, for certain subsets of happiness seekers, certain positive activities may be ineffective or even harmful. Without a complete understanding of how these activities work, and for whom they work, positive psychology-based activities - while a source of great potential for promoting well-being - should be disseminated with caution. 


\section{References}

Abramson, L. Y., Seligman, M. E. P., \& Teasdale, J. D. (1978). Learned helplessness in people: Critique and reformulation. Journal of Abnormal Psychology, 87, 49-74.

Ackerson, J., Scogin, F., McKendree-Smith, N., \& Lyman, R.D. (1998). Cognitive bibliotherapy for mild and moderate adolescent depressive symptomatology. Journal of Consulting and Clinical Psychology, 66, 685-690. doi: 10.1037//0022-006X.66.4.685

ACT, Inc. (2004). The Role of Academic and Non-Academic Factors in Improving College Retention (ACT Policy Report). Iowa City, IA: V.A. Lotkowski, S.B. Robbins, and R.J. Noeth.

Carey, K. (2004, May). A Matter of Degrees: Improving Graduation Rates in Four-Year Colleges and Universities. Washington, DC: Education Trust.

Compas, B. E., Wagner, B. M., Slavin, L. A., \& Vannatta, K. (1986). A prospective study of life events, social support, and psychological symptomatology during the transition from high school to college. American Journal of Community Psychology, 14, 241-257.

Cuijpers, P. (1997). Bibliotherapy in unipolar depression: A meta-analysis. Journal of Behavior Therapy and Experimental Psychiatry, 28, 139-147.

Cutrona, C. (1982). Transition to college: Loneliness and the process of social adjustment. In L. Peplau \& D. Perlman (eds.), Loneliness: A sourcebook of current theory, research, and therapy (pp. 291-309). NY: John Wiley and Sons.

Diener, E., Emmons, R. A., Larsen, R. J., \& Griffin, S. (1985). The satisfaction with life scale. Journal of Personality Assessment, 49, 71-75.

Flett, G. L., Vredenburg, K., \& Krames, L. (1997). The continuity of depression in clinical and nonclinical samples. Psychological Bulletin, 121, 395-416.

Friedlander, L., Reid, G., Shupak, N., \& Cribbie, R. (2007). Social support, self-esteem, and stress as predictors of adjustment to university among first-year undergraduates. Journal of College Student Development, $48,259-274$.

Howell, A. J. (2009). Flourishing: Achievemnet-related correlates of students' well-being. Journal of Positive Psychology, 4, 1-13.

Joiner, T. E. (1997). Shyness and low social support as interactive diatheses, and loneliness as mediator: Testing an interpersonal-personality view of vulnerability to depression. Journal of Abnormal Psychology, 106, 386-394.

Judd, L. L., Akiskal, H. S., \& Paulus, M. P. (1997). The role of clinical significance of subsyndromal depressive symptoms (SSD) in unipolar major depressive disorder. Journal of Affective Disorders, 45, 5-17.

Lewinsohn, P. M., Munoz, R. F., Youngren, M. A., \& Zeiss, A. M. (1992). Control your depression. New York, NY: Fireside.

Lyubomirsky, S. (2007). The how of happiness: A new approach to getting the life you want. New York, NY: Penguin Group.

Lyubomirsky, S., Dickerhoof, R., Boehm, J. K., \& Sheldon, K. M. (2011). Becoming happier takes both a will and a proper way: An experimental longitudinal intervention to boost well-being. Emotion,11, 391-402. doi: $10.1037 / \mathrm{a} 0022575$.

Lyubomirsky, S., King. L., \& Diener, E. (2005). The benefits of frequent positive affect: does happiness lead to success? Psychological Bulletin, $131,803-855$.

Mauss, I. B., Tamir, M., Anderson, C. L., \& Savino, N. (2011). Can seeking happiness make people unhappy? Paradoxical effects of valuing happiness. Emotion, 11, 807-815. doi:10.1037/a0024986

Milem, J. F., \& Berger, J. B. (1997). A modified model of college student persistence: Exploring the relationship between Astin's theory of involvement and Tinto's theory of student departure. Journal of College Student Development, 38, 387-400.
Naylor, E. V., Antonuccio, D. O., Litt, M., ,Johnson, G. E., Spogen, D. R., Williams, R., \& Higgins, D. L. (2010). Bibliotherapy as treatment for depression in primary care. Journal of Clinical Psychology in Medical Settings, 17, 258-271. doi:10.1007/s10880-010-9207-2

Ouweneel, E., Le Blanc, P. M., \& Schaufeli, W. B. (2011). Flourishing students: A longitudinal study on positive emotions, personal resources, and study engagement. Journal of Positive Psychology, 6, 142-153.

Parks, A. C. (2003). Developing a brief and cost-effective method of preventing depression and anxiety, promoting health and well-being, and fostering resilience in college freshmen. (Senior Thesis, Reed College).

Parks, A. C. (2003). Promoting subjective happiness during the transition to college. Poster presented at the 2nd International Positive Psychology Summit, October 2003.

Parks, A. C. (2004). Preventing depression with bibliotherapy. Poster presented at the 16th Annual Convention of the American Psychological Society, May 2004.

Parks, A. C., \& Biswas-Diener, R. (in press). Positive interventions: Past, present and future. To appear in T. Kashdan \& Ciarrochi, J. (Eds.), Bridging Acceptance and Commitment Therapy and Positive Psychology: A Practitioner's Guide to a Unifying Framework. Oakland, CA: New Harbinger.

Parks, A. C., Della Porta, M. D., Pierce, R. S., Zilca, R., \& Lyubomirsky, S. (2012). Pursuing happiness in everyday life: A naturalistic investigation of online happiness seekers. Emotion, 12, 1222-1234.

Parks, A. C., Schueller, S., \& Tasimi, A. (in press). Increasing happiness in the general population: Empirically Supported Self-Help? To appear in S. David, I. Boniwell \& A. C. Ayers (Eds.), Oxford Handbook of Happiness. Oxford: Oxford University Press.

Parks-Sheiner, A. C. (2009). Positive psychotherapy: Building a model of empirically supported self-help. Dissertations available from ProQuest. Paper AAI3363589. http://repository.upenn.edu/dissertations/ AAI3363580

Pavot, W., \& Diener, E. (1993). Review of the Satisfaction With Life Scale. Psychological Assessment, 5, 164-172.

Radloff, L. (1977). The center for epidemiologic studies depression scale: A self report depression scale for research in the general population. Applied Psychological Measurement, 1, 385-401.

Radloff, L. (1991). The use of the Center for Epidemiologic Studies Depression Scale in adolescents and young adults. Journal of Youth and Adolescence, 20, 149-166.

Schueller, S. M. (2010). Preferences for positive psychology exercises. Journal of Positive Psychology, 5, 192-203.

Schueller, S., \& Parks, A. C. (2012). Disseminating self-help: positive psychology exercises in an open online trial. Journal of Medical Internet Research, 14, e63.

Seligman, M. E. P., Schulman, P., DeRubeis, R. J., \& Hollon, S. D. (1999). The prevention of depression and anxiety. Prevention and Treatment, 2, 8 .

Seligman, M. E. P., Rashid, T., \& Parks, A. C. (2006). Positive psychotherapy. American Psychologist, 61, 774-788.

Seligman, M. E. P., Schulman, P., \& Tryon, A. M. (2007). Group prevention of depression and anxiety symptoms. Behavior Research and Therapy, 45. $1111-1126$

Sergeant, S., \& Mongrain, M. (2011). Are positive psychology exercises helpful for people with depressive personality styles? Journal of Positive Psychology, 6, 260-272.

Sheldon, K. M., \& Lyubomirsky, S. (2012). The challenge of staying happier: Testing the Happiness Adaptation Prevention model. Personality and Social Psychology Bulletin, 38, 670-680.

Wolf, T. M., Scurria, P. L., \& Webster, M. G. (1998). A four-year study of anxiety, depression, loneliness, social support, and perceived mistreatment in medical students. Journal of Health Psychology, 3, 125-36. 